Review article

\title{
Exposed to events that never happen: Generalized unsafety, the default stress response, and prolonged autonomic activity
}

\author{
Jos F. Brosschot ${ }^{\mathrm{a}, *}$, Bart Verkuil ${ }^{\mathrm{b}}$, Julian F. Thayer ${ }^{\mathrm{c}}$ \\ ${ }^{a}$ Health, Medical and Neuropsychology Unit, Institute of Psychology, Leiden University, Wassenaarseweg 52, 2333AK Leiden, The Netherlands \\ b Clinical Psychology Unit, Institute of Psychology, Leiden University, Wassenaarseweg 52, 2333AK Leiden, The Netherlands \\ ' Department of Psychology, The Ohio State University, Neil Avenue, Columbus, OH 43210, USA
}

\section{A R T I C L E I N F O}

\section{Article history:}

Received 22 January 2016

Received in revised form 5 July 2016

Accepted 19 July 2016

Available online $\mathrm{xxx}$

\section{Keywords:}

Default stress response

Chronic stress

Generalized unsafety

Perceived safety

Heart rate variability

Obesity

Loneliness

\begin{abstract}
A B S T R A C T
Based on neurobiological and evolutionary arguments, the generalized unsafety theory of stress (GUTS) hypothesizes that the stress response is a default response, and that chronic stress responses are caused by generalized unsafety (GU), independent of stressors or their cognitive representation. Three highly prevalent conditions are particularly vulnerable to becoming 'compromised' in terms of GU, and carry considerable health risks:
\end{abstract}

(1) 'Compromised bodies': in conditions with reduced bodily capacity, namely obesity, low aerobic fitness and older age, GU is preserved due to its evolutionary survival value;

(2) 'Compromised social network': in loneliness the primary source of safety is lacking, i.e. being part of a cohesive social network;

(3) 'Compromised contexts': in case of specific stressors (e.g. work stressors), daily contexts that are neutral by themselves (e.g. office building, email at home) may become unsafe by previously being paired with stressors, via context conditioning.

Thus, GUTS critically revises and expands stress theory, by focusing on safety instead of threat, and by including risk factors that have hitherto not been attributed to stress.

(c) 2016 Elsevier Ltd. All rights reserved.

\section{Contents}

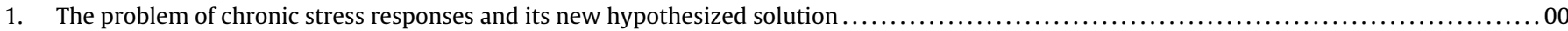

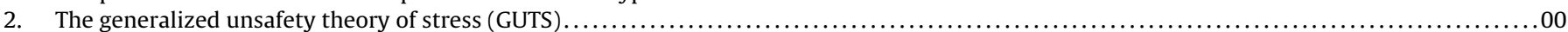

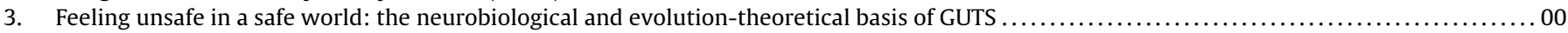

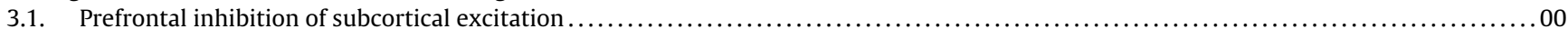

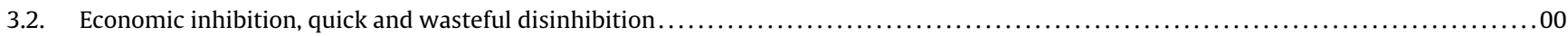

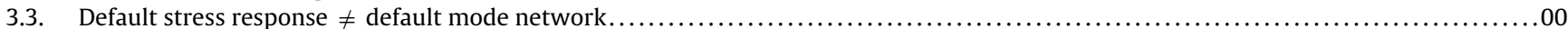

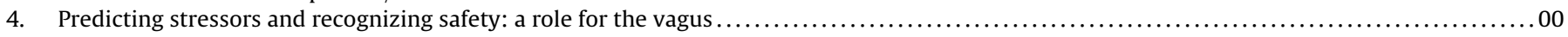

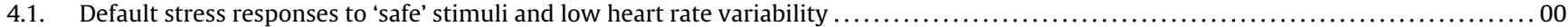

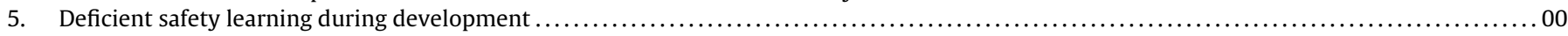

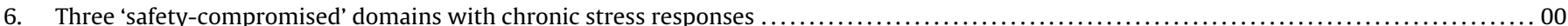

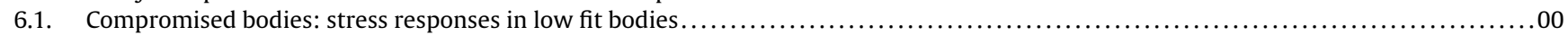

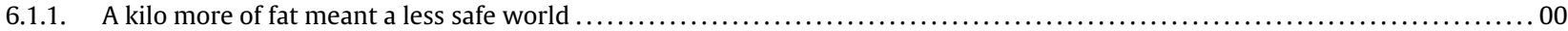

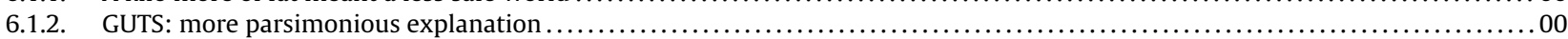

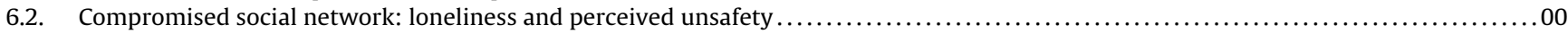

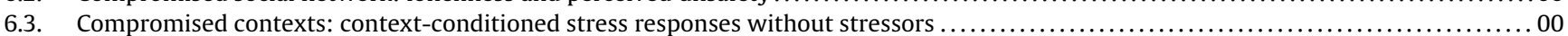

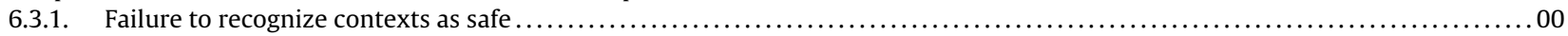

\footnotetext{
* Corresponding author.

E-mail addresses: brosschot@fw.leidenuniv.nl (J.F. Brosschot), bverkuil@fw.leidenuniv.nl (B. Verkuil), Thayer.39@osu.edu (J.F. Thayer).
} 
7. Concluding remarks.

\section{The problem of chronic stress responses and its new hypothesized solution}

Psychosocial stress, including chronic anxiety, is a major risk factor for somatic disease, including cardiovascular disease (Kiecolt-Glaser et al., 2002; Krantz and McCeney, 2002; Kubzansky and Kawachi, 2000; Roest et al., 2010; Rosengren et al., 2004; Searle and Bennett, 2001; Tully et al., 2013). The stressors for which this is best documented are work stress (Bosma et al., 1998; Matthews and Gump, 2002; Chandola et al., 2008), marital stress (Matthews and Gump, 2002; Orth-Gomer et al., 2000) and bereavement (Lee et al., 2003; Vitaliano et al., 2002). Still, the underlying psychophysiological mechanisms remain poorly specified. It is widely agreed that chronic physiological stress responses are the crucial causal factor leading to disease, but despite more than half a century of research, the precise causes of these chronic responses have not yet been sufficiently revealed. Conventional stress theories still embrace the reactivity hypothesis that holds that multiple intense responses during stressors are important. These theories neglect a crucial aspect: the duration of the exposure that often outlasts the stressful events themselves. We previously hypothesized that actually occurring stressors are far less important than what happens in people's thoughts, that is, their cognitive representations of stressors, termed 'perseverative cognition' (PC; Brosschot et al., 2006; see also Fig. 2a). PC may even be largely unconscious (Brosschot, 2010; Brosschot et al., 2010) but still leads to prolonged physiological stress responses (ibidem). PC is not only a core element chronic stress, but also in chronic anxiety, and the latter can be easily conceptualized as a chronic psychobiological stress response in the absence of realistic stressors (e.g. Hoehn-Saric et al., 2004; Licht et al., 2009; Thayer et al., 1996). Despite growing evidence that PC causes prolonged physiological responses, especially for cardiovascular and endocrine (i.e. cortisol) activity (Brosschot et al., 2006; Ottaviani et al., 2015; Verkuil et al., 2010; Zoccola and Dickerson, 2012), it is still far from explaining most of, let alone all of, the often extremely protracted stress responses associated with chronic stressors such as work stress, marital stress or loneliness, chronic anxiety, and their psychophysiological concomitants such as continuously increased rest levels of blood pressure, cortisol or low heart rate variability (HRV; Robles and Kiecolt-Glaser, 2003; Thayer et al., 2010). What causes these, often truly chronic, responses, which over time will result in biological dysregulation (Brosschot et al., 2006), or 'allostatic load' (McEwen and Seeman, 1999)? It seems unlikely that people think incessantly about their stressors, either consciously or unconsciously (this problem is illustrated in Fig. 1a-c). But if PC cannot sufficiently explain truly chronic responses what else explains them? In this article, we take a radically different viewpoint by posing that not PC but the automatic (i.e. largely unconscious) 'generalized perception of unsafety' is the crucial explanatory mechanism. How might this new idea solve the problem of what causes chronic physiological responses that, in the long run, lead to disease? Using a new theoretical approach, called the "Generalized Unsafety Theory of Stress" (GUTS), we propose that the solution lies in the fact that the way in which the problem is phrased is wrong.

\section{The generalized unsafety theory of stress (GUTS)}

Current neurobiological evidence (e.g. Ahern et al., 2001; Amat et al., 2005; Motzkin et al., 2015; Grupe and Nitschke, 2013; see below) and evolutionary reasoning (e.g. Nesse, 2005; Trimmer et al., 2013 see below) imply that the stress response is a default response of the organism, and that it is the response the organism automatically falls back upon when no other information is available. So, the problem should not be formulated as: "what causes chronic stress responses?" but as "what mechanism allows the default stress response to be turned off?-and when does this 'switch off' mode fail to work?" To answer this last question is the chief goal of this article. We hypothesize that the mechanism that explains most chronic stress responses in daily life is the generalized perception of unsafety (GU), that is largely automatic (and as a result mainly unconscious). The argument in a nutshell: GU causes the default stress response to remain activated, whenever our phylogenetically ancient mind-body organism fails to perceive safety in a wide range of situations in modern society that are not intrinsically dangerous. This new explanation forms a radical shift from current stress theory - including our own PC hypothesis - that focuses on stressors and PC. It comprises a completely new theory called, as mentioned, the "Generalized Unsafety Theory of Stress" (GUTS). A key principle of GUTS is that not being able to switch off, or inhibit the default stress response is not dependent on actual stressors or PC: perceived GU is sufficient, GU is the crucial element here. Due to GU, chronic stress responses occur in an objectively safe world, with no threatening information. The GUTS has a far greater explanatory ability than other current stress theories. Most esentially, as we will explicate below, it predicts how prolonged and even chronic stress responses occur when no actual stressors (threats) are present at all, or even cognitive representations of stressors, because of the continuous failure to perceive safety. Therefore, it can explain a much higher number of hypothetical situations in which stress responses may occur. For large groups of people, this means all situations, e.g. in people with a so called 'compromised' body or social network, as we shall explain below. GUTS is thus likely to be far better at explaining prolonged or chronic stress-related physiological activity. With increasing chronic stress as well as booming health care costs in our society it is very timely to test this new theory. We will further detail the hypotheses of GUTS below.

Before doing so, we would like to point out that these hypotheses pertain not only to stress but also to anxiety and its (neuro)physiological concomitants. As mentioned above, in terms of stress theory anxiety can be viewed as a stress response without actual stressor, and neuroscientists commonly treat stress and anxiety as the same subject because of their shared neurobiology. We have discussed the relevance of GUTS for anxiety in more detail elsewhere (Brosschot et al., 2016).

\section{Feeling unsafe in a safe world: the neurobiological and evolution-theoretical basis of GUTS}

It might feel somewhat counterintuitive that an intensely powerful and primary survival mechanism such as the chronic stress response is sparked off by the mere absence of something like perceived safety, instead of the presence of something profound like a threatening situation, or disturbing thoughts thereof. Yet, precisely because the stress response is a primary survival mechanism, it should be the response to automatically and immediately fall back upon when the only information that could stop it, i.e. proof of safety is not available. Organisms have survived in evolution not by waiting for more evidence of threat but instead by erring on the side of caution (e.g. Nesse, 2005; Trimmer et al., 2013), or, popularly 
a Conventional stress theory: stressors

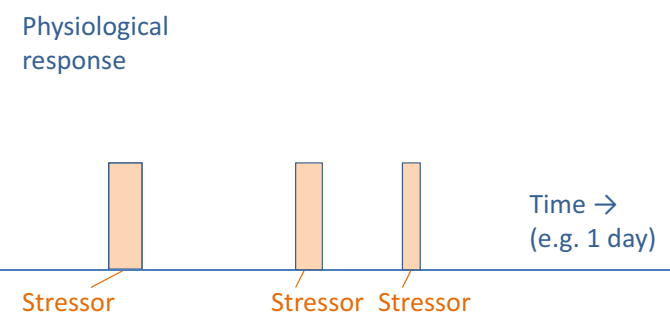

c Idem, but: no stress response in the remaining time?

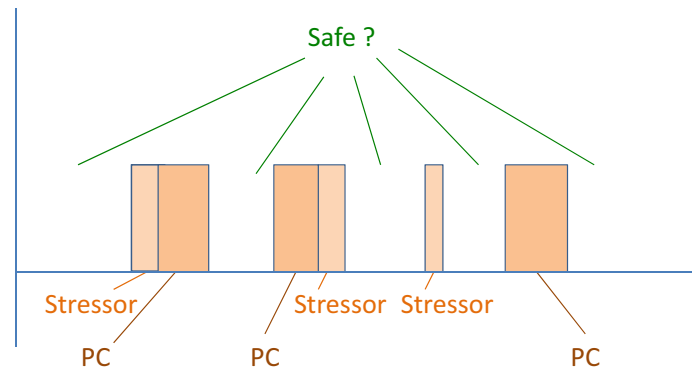

e Generalized unsafety theory of stress (GUTS): Stressors, PC, plus unsafe stressor-conditioned contexts

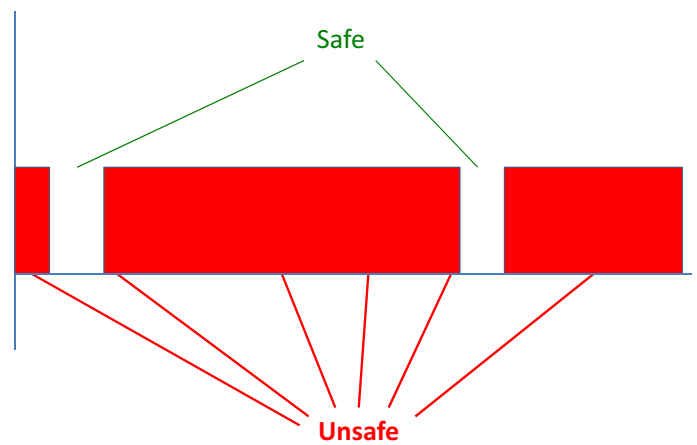

b Perseverative cognition (PC) theory: stressors plus PC

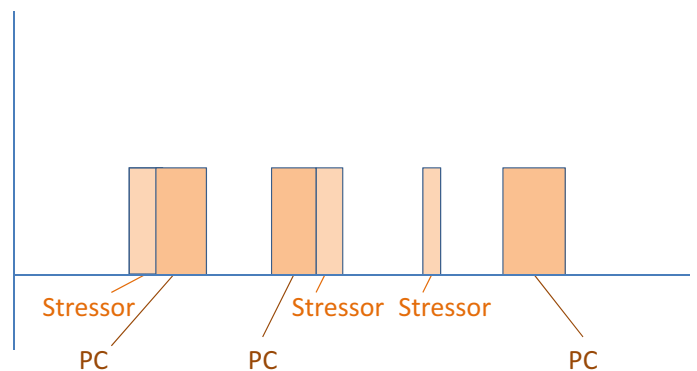

d Generalized unsafety theory of stress (GUTS): Stressors, PC, plus unsafe stressor-conditioned contexts

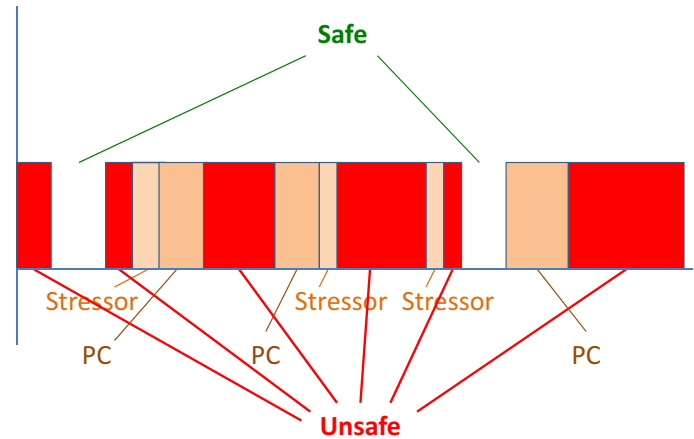

f Chronic unsafety (e.g. 'compromised bodies' \& loneliness)

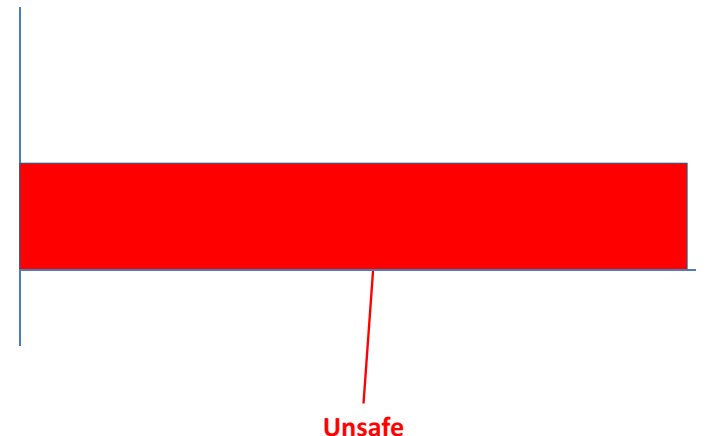

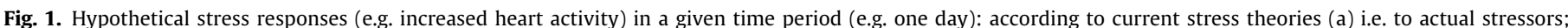

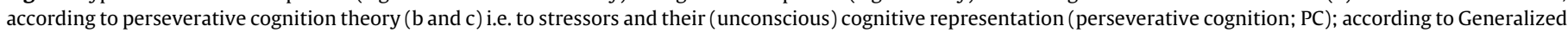

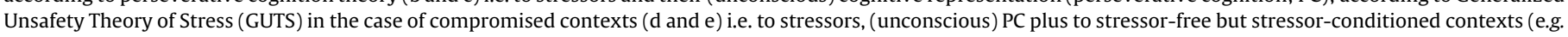

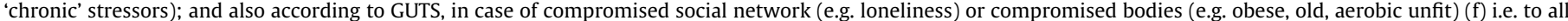

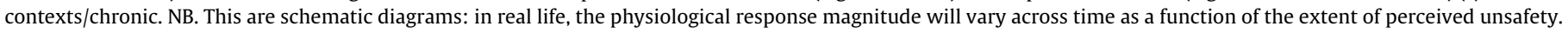
Adapted from Brosschot et al., 2016.

formulated, to be 'better safe than sorry'. For this reason the stress response is default, it is 'always there', on the verge of being activated, only being inhibited when safety is clearly perceived.

This evolutionary line of reasoning is supported by several - new but also old - neurobiological insights, especially concerning the role of the prefrontal cortex in regulating subcortical sympathoexcitatory default activity, and the ease and speed of the default stress response, and conversely, the low cost nature of its (long-term) inhibition.

\subsection{Prefrontal inhibition of subcortical excitation}

The stress response is mediated by subcortical areas in the brain, i.e. the so called limbic structures, including the amygdala, and it is normally under continuous ('tonic') inhibition by the prefrontal cortex (PFC; Ahern et al., 2001), more specifically by the ventromedial PFC (vmPFC; Motzkin et al., 2015). When safety is in doubt, subcortical inhibition by the vmPFC is decreased and amygdala activity is enhanced (Grupe and Nitschke, 2013). This happens even long after a stressor has stopped, when safety is still in question 

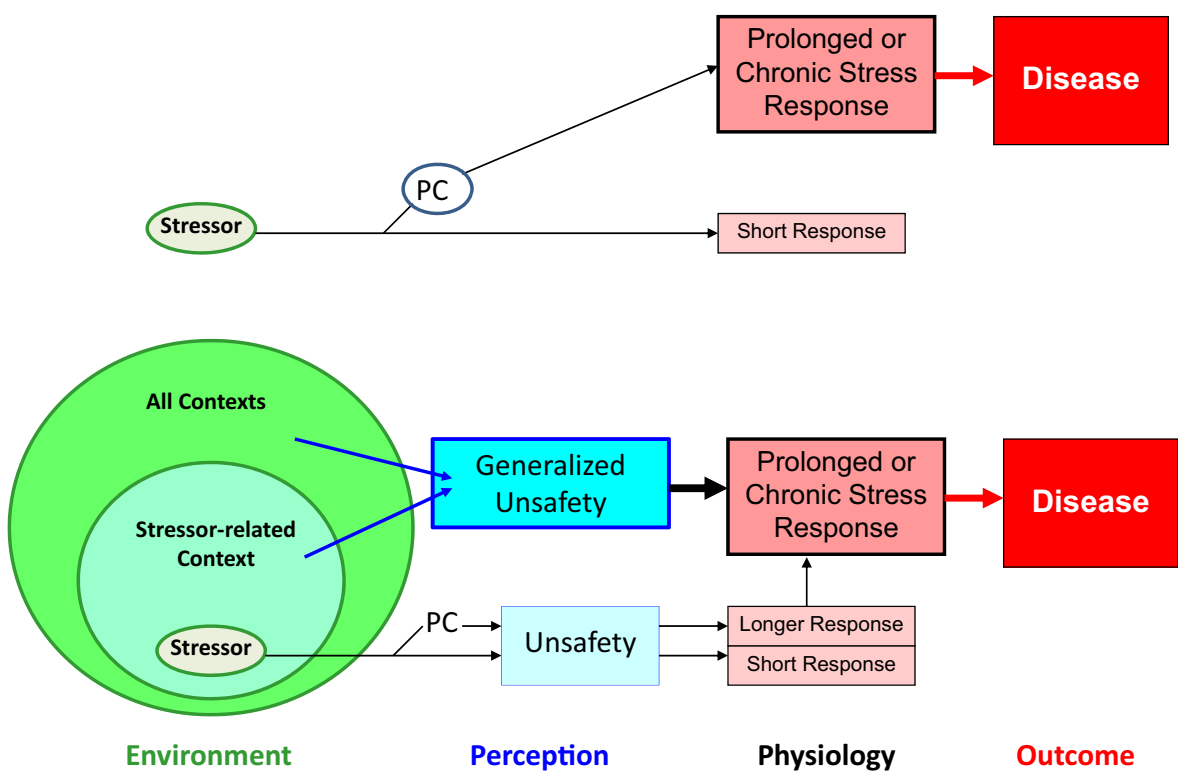

Fig. 2. Generalized Unsafety (GU) explains far more physiological stress responses than stressors and (unconscious) PC, leading to somatic disease. Adapted from Brosschot et al., 2016.

(van Marle et al., 2010), and chronically - even when no threats are present - for example in humans and animals with chronic anxiety (Grupe and Nitschke, 2013). Conversely, during a stressor that turns out to be safe (controllable) amygdala activity is again inhibited by the PFC (Motzkin et al., 2015). The notion that removal of prefrontal inhibition "permits" rather than "causes" an increase in physiological activity (disinhibition) is consistent with the old but unduly overlooked 'Hughlings Jackson principle of hierarchical integration through inhibition' (Hughlings Jackson, 1884; see also Thayer et al., 2012). According to this principle, phylogenetically old responses (such as the stress response), are in Jackson's words “not 'goaded into activity,' but are 'let go"'. It is supported by studies showing that the amygdala has the lowest spontaneous firing rate (indicating tonic inhibition; Quirk and Gehlert, 2003), and that experimental PFC inactivation in human volunteers by internal carotid artery injections of sodium amobarbitol increases heart rate HR and lowers HRV, - without any stressor! - which is less so in older individuals (Thayer et al., 2009), which is in fact consistent with GUTS (see Section 3.3 below). Furthermore, it has been shown that patients with vmPFC damage show diffuse resting-state amygdala functional connectivity to non-prefrontal areas (Motzkin et al., 2015), and importantly we have recently shown that resting state amygdala-mPFC connectivity is positively correlated with resting HRV (Sakaki et al., 2016). In addition, we have shown that mPFC-pons connectivity during a subjective emotional experience task was negatively correlated with depressive symptoms and positively correlated with HRV during the emotion task (Smith et al., 2015). Several studies suggest that in both task-related and resting state studies as well as in trait anxiety the top-down regulation by the PFC of the amygdala is diminished (Kim and Whalen, 2009; Kim et al., 2011a, 2011b; Davidson and McEwen, 2012; Urry et al., 2006). Kim et al. (2011a) for example demonstrated negatively correlated amygdala-ventral mPFC functional connectivity at rest in high anxious individuals, in contrast to positively correlated activity in low anxious subjects. This role for the vmPFC was also shown in animal studies vmPFC (e.g. Maier, 2015). Thus, the stress response is not triggered, but disinhibited. This has been overlooked by modern stress science. The presence of safety inhibits stress-induced neural activity, in contrast to the prevalent view that such activity is induced by a lack of control (Amat et al., 2005). Importantly, this inhibition appears to be at least partially dependent upon the prefrontal cortex inhibiting subcortical sympathoexcitatory circuits (Thayer, 2007).

\subsection{Economic inhibition, quick and wasteful disinhibition}

It hardly takes any time to 'err on the side of caution' and decide that the world is not safe, while it takes time and effort to decide that it is. This for example is shown by the finding that a positive ('safe') interpretation of ambiguous facial expressions of surprise takes longer and takes more effort (and higher vmPFC activation) than a negative interpretation ('unsafe'; Kim et al., 2003). One might counter-argue that to continuously inhibit the default stress response during times of safety would be too costly. However, from an evolutionary perspective one would expect that individual organisms spending minimum energy on a survival mechanism that preferably operates continuously will have had the highest chance to pass on their genes. It appears that inhibitory neural action indeed requires considerably less energy than excitatory action, there are far less inhibitory neurons than excitatory neurons in the brain, with far more general connections across the central nervous system (Waldvogel et al., 2000). This suggests that the inhibitory neurons act in a non-costly and highly generalized manner with immediate and profound effects. Thus, the inhibition of the default stress response when safety is perceived, may take time to be established, but it is not costly to prolong it. On the contrary, its disinhibition takes little time, but is costly, and when prolonged it may lead to biological dysregulation and disease. Being default and at the same time costly underscores that being default is not the same as being the 'desired state'. It is simply the state to return to when no information (i.e. about safety) is available.

\subsection{Default stress response $\neq$ default mode network}

If the brain is 'at rest', a term neuroscientists use meaning that it is not involved in a task assigned by the experimenter, a neuronal network is activated containing many brain regions (Raichle et al., 2001) that actively inhibit subcortical responses including 
stress responses. In GUTS terminology the brain is then 'perceiving safety'. Confusingly, this resting state network goes by the name default mode network (DMN; Raichle et al., 2001). Importantly, the use of default here is correct to the extent that it means 'default with respect to experimental tasks'. However, it is not default in the sense we described above: the response that the organism automatically falls back upon when no other information is available, that is, a state of uncertainty about safety, for which, we argue, organisms are naturally intolerant: organisms are intolerant for uncertainty by default. Thus, during activation of the brain's 'default mode network', the default stress response is typically inhibited.

\section{Predicting stressors and recognizing safety: a role for the vagus}

The brain is often viewed as a "prediction machine", serving major life goals. It proactively activates possible scenarios (Bar et al., 2007), continuously calculating safety. As long as the outcome is 'safe', the default stress response is inhibited by the vmPFC. If the prediction machine works optimally, it will detect safety cues except during the clear presence of a stressor. When stressors cannot clearly be predicted, the safety of the surroundings is not guaranteed, and the stress response remains disinhibited, even in the (temporal) absence of stressors. Safety signals have been shown to be learned cues that predict the stress free periods (Christianson et al., 2008).

The importance of recognizing safety became obvious in the now classic studies by Weiss and co-workers (see Weiss, 1970) which showed that unpredictable stressful stimuli (e.g. electric shocks, noise) caused a host of deleterious physiological outcomes. The predictability paradigm became an important model for stress, depression and anxiety (Davies and Craske, 2015; Grillon et al., 2009; Mineka and Kihlstrom, 1978; Woody and Rachman, 1994). The stress reducing effect of predictability was generally explained in terms of recognizing safe periods between the stressful stimuli. In other words, the animal or human subject knew that during a given period no harm would happen. Unpredictability of adverse stimuli undermined this expectation: the adverse stimulation could now occur anytime, and the time between stressors had become unsafe. However somehow, during the last half a century, stress researchers (including our colleagues and ourselves) have - again - been missing the most important point here: the crucial - because prolonged - stress responses did not occur during the unpredictable stressors, but during the periods in between stressors! Again, it is to the objectively neutral (but uncertain) periods that responses are initiated and maintained - due to not recognizing safety.

Importantly, more recent studies have shown that even if safety cues are available, they are often not recognized (e.g. Maren et al., 2013; Melzig et al., 2009; Pappens et al., 2014; Ruiz-Padial et al., 2003; Wendt et al., 2015). Moreover, not recognizing safety is not restricted to people suffering from stressors or anxiety (Pappens et al., 2014; Ruiz-Padial et al., 2003; Wendt et al., 2015). As we will discuss below, there are individual and state-dependent influences on not recognizing safety that appear to be strongly associated with the activity level of the autonomic nervous system, especially the parasympathetic branch, served mainly by the nervus vagus and therefore often called vagal activity. High vagal activity is reflected in high heart rate variability (HRV). In fact, merely having a low resting heart rate variability (HRV) seems sufficient for not recognizing safety, and thus GU.

\subsection{Default stress responses to 'safe' stimuli and low heart rate variability}

HRV has been shown to be an easily accessible measure of vagus nerve activity. For example, it has been shown in a rodent model that high frequency HRV correlates 0.88 with vagus nerve activity (Kuo et al., 2005). The vagus has been shown to be important in the regulation of a number of physiological systems besides the cardiovascular system including inflammation, glucose, and lipids. Thus low HRV has been associated both cross-sectionally and longitudinally with inflammation, glucose levels, and cholesterol levels (Thayer and Fischer, 2009, 2013; Jarczok et al., 2014, 2013). Furthermore, HRV has been shown to be more closely related to self-rated health that a broad panel of biomarkers (Jarczok et al., 2015). Importantly, an age- and gender-adjusted clinical cut-point for HRV as indexed by the root mean squared successive difference (RMSSD) has been suggested such that persons with daytime RMSSD below $30 \pm 5 \mathrm{~ms}$ are at greater risk for a number disorders (Jarczok et al., 2015).

HRV is important for GUTS because low HRV, as a measure of parasympathetic (vagal) withdrawal, i.e. the critical, autonomic stress response, is strongly linked to PFC-inhibition of subcortical areas (e.g. Smith et al., 2015). For optimal survival, the disinhibition of the response to threat must be as immediate and fast as possible. This is why it is a default response, that is 'always ready', only to be inhibited when safety is clear, as argued above. This instantaneous disinhibition requires a system that is extremely fast and located all over the body, since the whole body is involved in the stress response. The vagus is such as system (Berthoud and Neuhuber, 2000). Therefore, in GUTS terminology, low resting HRV ('vagal withdrawal') is an index of the chronically disinhibited default stress response.

Showing physiological stress responses to safe (neutral) stimuli has been found to be associated with low HRV (Pappens et al., 2014; Ruiz-Padial et al., 2003; Wendt et al., 2015). Specifically, low HRV has been shown to predict psychophysiological stress responses to safe (neutral) stimuli, and thus implying GU, using a variety of experimental paradigms. For example, low HRV predicts a high startle response to neutral stimuli in men (Ruiz-Padial et al., 2003) and diminished safety learning, i.e. fear responses in fear conditioning to CS- as well as CS+, or slow extinction (Pappens et al., 2014; Wendt et al., 2015) and, in contrast, amplified contextual fear conditioning (Melzig et al., 2009), that is, generalizing stress responses from the fearful CS+ to a wider context (environmental/social; Maren et al., 2013), i.e. the context as CS+. Thus: GU is linked to low HRV, even when stressors are absent.

\section{Deficient safety learning during development}

At the start of our life, when we leave the safe uterine world, we all start with the default stress response, but soon we learn to predict the safety signals around us: the conditions under which hunger and thirst are satisfied, when affiliation needs are being met, reflected in an increasing HRV (Porges, 2007). During our life our brains learn the increasing complexity of the contingencies of safety and their generalizability toward new people, situations and environments, and thus when and where to inhibit the default stress response.

It is a truism to say that threats (stressors) are unavoidable in life, but in reality, their actual presence is very much restricted in time and place, even in our ancestral surroundings. During maturation young humans as well as young animals acquire an increasingly complex fear learning capacity (see Glenn et al., 2012). Importantly, the direction of learning is not from no fear toward anxiety but from general anxiety toward specific fear. In other words, they 
start with a general default stress response, after which the developing animal or human gradually learns about the predictability and controllability of threats in life. It should be noted here that despite conceptual, behavioral and neurobiological (Christianson et al., 2008) differences between predictability and controllability, their net results in terms of perceived safety and physiological responses can be assumed to be comparable. There is increasing evidence that experiences of control even 'immunize' against successive uncontrollable situations (contexts) and generalizes across similar contexts (Maier, 2015), and adolescence may be the sensitive period for this type of learning. An experiment by Kubala et al. (2012) suggested that for adolescent rats but not adult rats, experiencing a controllable stressor (e.g. escapable shock) is not only fundamental to 'immunize' the rat for its entire lifespan, but that this is also better than not experiencing a controllable stressor at all. Hence, it is important that organisms experience stressors and also develop some experience with control of stressors. If an organism never experiences a stressor it will never learn the capacity to control stressors, and thus safety.

This contingency learning about safety can be successful in different degrees and fail in many ways. Some of these 'failures' seem to determine relatively stable, change-resistant GU, such as inherited psychological vulnerability (e.g. traits such as neuroticism), chronic prenatal maternal stress and chronic early life stress. In terms of GUTS, in these conditions a deficient inhibition of the default stress response is brought about on different developmental levels: it is either passed via genes (suggesting limited safety in one's specific ancestral past), or via the prenatal or perinatal neurobiological milieu (suggesting limited safety in these periods) or safety contingency learning is prevented due to a lack of clear safety cues in postnatal early life (e.g. in case of abuse or emotional neglect). In line with this, chronic early life stress - as opposed to the controllable acute stressors mentioned above - has been found to be associated with low HRV (Dale et al., 2009; Heitkemper et al., 2011). Moreover, a number of studies have documented deficits in both anatomy (e.g. gray matter volume) and connectivity in the prefrontal-limbic network due to prenatal and early life stress in both animals and humans (see Tost et al., 2015; van Harmelen et al., 2010). The usual explanation for these findings is often formulated in terms of neural damage or retardation of normal neural growth. This might be the case for very severe (traumatic) stressors. However, according to GUTS it is more likely that chronic early life stress prevents the brain from learning the complexities of safety contingencies, and thus from growing the neural structures subserving this knowledge. Likewise the enhanced stress vulnerability in later life associated with chronic early life stress (see Tost et al., 2015), might not or not only be the result of 'damage' or 'reprogramming' but for a large extent of a deficient inhibition of the default stress response, due to not learning sufficient safety cues.

Other safety learning failures theoretically more amenable to change can occur and produces GU later in life. In our view there are three distinct major domains that are particularly vulnerable to the development or maintenance of GU later in life: our body, that should be sufficiently capable to deal adequately with the threats of our ancestral habitat; our social network, which should provide the primary safety signal for social animals such as humans; our context, which in modern society is, despite occasional threats, overwhelmingly safe compared to - again - our ancestral habitat. We call these domains compromised, when they fail to contribute to perceptions of safety. We chose these three domains not only because their 'safety failures' are potentially changeable, but also because when 'compromised' they carry highly prevalent major risk factors for somatic disease in modern society: in our body, e.g. obesity, old age or aerobic unfitness; in our social network, e.g. loneliness, and our daily contexts may become unsafe through contextual fearconditioning. This basically implies that some of the biggest - and growing - health risks in modern society (obesity, aerobic unfitness etc. and loneliness) may be at least partly due to chronic stress responses! We will explain below why this is possible.

\section{Three 'safety-compromised' domains with chronic stress responses}

Taken together, the major hypothesis of GUTS is that prolonged physiological stress responses are caused by generalized perceptions of unsafety (GU). This will be illustrated by three compromised domains that carry considerable somatic health risks. We will now point out what we mean with each compromised domain and why we hypothesize that the chronic physiological responses associated with them are due to GU.

\subsection{Compromised bodies: stress responses in low fit bodies}

A large range of conditions that are, at first glance, not directly related to stress, such as obesity, low aerobic fitness and old age (Thayer et al., 2010; Zulfiqar et al., 2010) and many other 'low capacity' bodily states (Thayer et al., 2010), are still associated with chronic low HRV. Are people in these conditions chronically 'stressed'? This is indeed what we hypothesize. In terms of GUTS: these people are not recognizing sufficient safety to inhibit the default stress response. The generalization of safety (or unsafety) is, partly, a function of our fitness, that is, our physical capability to cope with stressors. This is for example clearly evident from the common experience that when not 'feeling well' we perceive challenges to be much. A possibly less evident example is that it has been consistently found that various forms of bodily unfitness cause a overestimation of physical challenges: for example they make a distance to a target seem greater and a hill seem steeper (Proffitt, 2006). Bodily information, mediated by afferent visceral neural pathways, sometimes referred to as "gut feelings" - although they are largely unconscious - is an inseparable part of the organism's emotional state (Damasio, 1991; Mayer, 2011). This includes predicted safety. However, we propose that the influence of 'fitness' goes way beyond merely 'not feeling well'.

\subsubsection{A kilo more of fat meant a less safe world}

In earlier stages of our evolution, an obese body meant a serious reduction in fight/flight ability in the face of the ubiquitous threats of ancestral life. For millions of year, even a single kilo of excess fat meant a somewhat lower capacity to exert a fight or flight response to e.g. predators, alien tribes, intra group violence, various threats to one's offspring etc. The same was true for all other conditions that compromise the body's fitness, such as low aerobic fitness, older age, fatigue, illness and pain, even though e.g. obese or older people can be relatively fit. The world was generally less safe for people in these conditions, and it had survival value not to inhibit the default stress response. Importantly, despite the increased objective environmental safety, modern human bodies still respond in a similar manner. Therefore, in all these conditions the stress response is more 'on edge', as reflected in a low HRV (Thayer et al., 2010; Zulfiqar et al., 2010). In neurobiological terms, a compromised body does not provide sufficient bodily information to allow the brain to predict complete safety (Smith et al., 2015). With such a lack of information the system falls back upon the default and therefore the default stress response is chronically active (i.e. not inhibited, as reflected in low HRV), and as is illustrated in Fig. $1 \mathrm{f}$ and in Fig. $2 \mathrm{~b}$ ('all contexts'). GUTS proposes that this explains a considerable part of the autonomic imbalance and high disease risk that accompanies these conditions. (cf., Julius, 1995). 


\subsubsection{GUTS: more parsimonious explanation}

Although in each of these very different conditions (i.e. older age, obesity, etc.) there are biological pathways that may partially explain low HRV, GUTS is the first theory that explains the chronic low HRV that they share by an overarching principle - GU and the default stress response - which is much more scientifically parsimonious. Julius (1995) argued before that autonomic imbalance as indexed by chronic low HRV in overweight and related conditions such as diabetes was due to chronic 'hypervigilance' or 'defense' responses. However, he did not generalize this to other 'compromised body' conditions, and did not interpret those responses in terms of default stress responses caused by GU. One might say that obese, aerobically or otherwise unfit, and older persons are actually enduring (largely unnoticed) chronic stress or anxiety because in these bodily conditions no safety signal can be detected with respect to their physical ability to deal with stressors. Yet, although we expect that in these conditions, high levels of GU will be observed - which largely remains to be tested - it is likely that not all (older, unfit, obese) people will report chronic increased levels of stress, perhaps because of the gradual onset and continuance of their stress, and because their world only gradually became more uncertain in terms of safety. Better to phrase it in GUTS' terminology: they are deficient in inhibiting the default stress response because of generalized unsafety (GU) - in the absence of any (even uncertain) threats.

\subsection{Compromised social network: loneliness and perceived unsafety}

A second domain in which perceptions of unsafety may become generalized, is that of the personal social network - or the lack thereof. For social animals such as humans, the social safety signals are the most important (cf. Coan's Social Baseline Theory; Coan, 2010). Specifically, belonging to a cohesive and supporting social network or simply perceiving sufficient friendly people around appears vital (Cacioppo et al., 2015) and is linked to an increased HRV (Porges, 2007). However, increasingly more people in the modern world have weak or virtually non-existent social networks. Loneliness (perceived social isolation; Cacioppo et al., 2015 ) is rapidly growing in modern society presumably due to a vicious combination of 'graying' and individualization. Loneliness predicts increased morbidity and mortality even after adjusting for health behaviours (ibidem). A recent study suggested that social isolation rather than the perception of loneliness is responsible for higher mortality (Steptoe et al., 2013). Evidence is growing for chronic autonomic (including low HRV) and endocrine stress responses in lonely animals and humans which likely mediates their health risk (ibidem; Hawkley et al., 2003). A recent study even found a dose response relationship between lower social integration and physiological dysregulation (Yang et al., 2016). However, although loneliness is associated with chronic stress responses, there is no particular stressor in loneliness that is responsible for its health risks. The most important ill health causing aspect seems to be the continuous lack of something important, namely social contact. In terms of GUTS, loneliness is a condition in which the social network is compromised, that is, the primary source of safety is generally unavailable. We argue that it is GU that is the cause of the chronic stress responses in loneliness, and not stressors, as illustrated in Fig. 1f and in Fig. 2b ('all contexts').

Interestingly, in another common condition in which the social network is compromised, that is social anxiety, chronic low HRV has been reported (e.g. Licht et al., 2009).

\subsection{Compromised contexts: context-conditioned stress responses without stressors}

The generalization of safety (or unsafety) is not only a function of the capacity of the body and the availability of primary safety (social network), but also of learning experiences. So, the third personal domain in which GU and low HRV may occur is in situations, or environments that are neutral (safe) by themselves, but that have acquired a threat value by their association with a stressor, through context conditioning (Grillon et al., 2006; Melzig et al., 2009). For example, responses to the working environment can become context-conditioned (Maren et al., 2013) because of the potential presence of bullying colleagues, or responses to the home environment in the case of marital discord. Again, the point here is that neither stressors nor their cognitive representation (PC), whether conscious or unconscious, are necessary for a chronic default stress response to remain activated (i.e. not inhibited). As mentioned earlier, each normal life contains multiple stressors that are unavoidable, and all of us, even those with superior coping skills and generalized perceptions of control (e.g. having high optimism or having an internal locus of control), have to face the fact that there are always stressors on the horizon. To maintain good health it is therefore important to restrict our stress responses as much as possible to episodes in which stressors actually happen, and to brief periods of 'productive' PC, i.e. problem solving. As a metaphor, one can think of the antelope that never runs further away from the lion (the ever present stressor) than necessary to allow for sufficient time (the safe period) to easily escape from the next attack. Obviously, many of us do not succeed in this, and cognitively perseverate a lot in between stressors, consciously or unconsciously, causing a lot more stress responses than are strictly necessary, as illustrated in Fig. 1b. However, the novel insight proposed here is that many people show far more stress responses in the long stretches of time between stressors and also when they do not think about these stressors, i.e. conscious or unconscious PC, as is illustrated in Fig. 1c and d. Thus, the stress-related contexts do not only cause prolonged disinhibition of the default response by triggering (un)conscious stress-related thinking, but also, and much more often, by failing to offer a perception of safety.

\subsubsection{Failure to recognize contexts as safe}

Fear (stress) responses can therefore be conditioned to the wider environment, i.e. the context, in which a threatening stimulus (stressor) occurred earlier. One example is work stress, of which health risks and chronic stress responses have been well documented. For example, scoring in the highest quartile of work stress increases cardiovascular disease risk up to 3.6 times (Bosma et al., 1998) in a dose response fashion (Chandola et al., 2008), with follow-up times of between 4 and 12 years. GUTS's hypothesis is that people suffering from any type of work stress show prolonged low HRV in work related contexts without actual stressors or PC, and that these low HRV responses are due to GU. For example, in the case of the work stress type of bullying, which forms a serious health risk (Nielsen et al., 2012; Verkuil et al., 2015), the stress response, that is initially linked to the real situation of being bullied, might get linked to contexts related to work (office, building, area, email at home, etc.) and even to non-stressor-related but work-related thoughts. In this way many stressor-free but stressorrelated contexts, in which we spend a large part of our daily life, may become - largely unconsciously - perceived as unsafe and lead to a protracted disinhibition of the default stress response. Crucially, this is also the case when we do not have any (un)conscious stress-related thoughts (PC), either triggered or not by these contexts. In other words: stress-related cognition is no requirement for a continued default stress response. The latter can in fact continue until the stressor-free but stressor-related context is abandoned, 
whether that context is real or merely cognitive represented. There are virtually endless realistic combinations of stressors leading to GU to their contexts and subsequent seriously protracted stress responses. For example, people suffering from the stressor of financial debt carry an increased risk for disease (Rosengren et al., 2004). They may very frequently fail to shut down their default stress response not so much because of the number of actual exposures to their stressor or thoughts thereof, but far more by being faced almost continuously with a myriad of contexts that are associated with the stressor, that have become 'unsafe': e.g. shops, financial newspaper pages, signs of Euro's (or other currencies), wallets, banks. Another example is the teenager fearing social exclusion who has a disinhibited default stress response during the many hours of handling a smart phone or computer - again without these devices necessary triggering any conscious or unconscious PC. Or the situation of caregiving for a spouse with Alzheimer, which is associated with enhanced cardiovascular risk (Lee et al., 2003), how many cues in one's surroundings irrespective of the presence of the spouse, or stress-laden thoughts of him/her, sustain GU and therefore the disinhibition of the default stress response?

Clearly, there are many examples of how GU can develop in originally safe contexts. Obviously, this greatly expands the likelihood for prolonged stress responses and related health risk. The different effects of relatively short stress due to stressors and PC and much more prolonged stress responses due to GU and their effects on somatic disease are illustrated in Fig. $2 \mathrm{~b}$ below.

An extreme example of the compromised domain of context is generalized anxiety disorder (GAD), sufferers of which do not only worry in virtually every context, but because of their continuously low HRV (Hoehn-Saric et al., 2004; Thayer et al., 1996 seem to be “extremely contextually conditioned” (see Brosschot et al., 2016).

\section{Concluding remarks}

The generalized unsafety theory of stress, GUTS, proposes an entirely new theoretical perspective on stress, based on evolutiontheoretic and neurobiological reasoning. The two core ideas are that: (1) the stress response is a default response that is normally under tonic inhibition; (2) when no safety is perceived, the default response remains uninhibited. Chronic stress is not due to the presence of something (i.e. stressors, threat) but the lack of something else: safety. Chronic stress responses are due to generalized unsafety (GU). Only when safety is detected, there is PFC inhibition of subcortical areas, especially the amygdala, which is refelected by a high resting HRV. If not, regardless of presence of any stressor or its cognitive representation, PFC inhibition is withdrawn, and the default stress response is unleashed, reflected in a low HRV. In healthy, well-adapted organisms, PFC inhibition is the norm, which is consistent with the finding that neural inhibition is non-costly and highly generalized. In contrast, PFC disinhibition of the default stress response, is costly, and can cause chronic bodily dysregulation and somatic disease.

We identified three domains of life in which GU can develop and which we call 'compromised': (1) 'Compromised bodies': e.g. obesity, low aerobic fitness and older age, in which GU is preserved due to its evolutionary survival value, i.e. to lower the threshold for the stress response because of a reduced bodily capacity to deal successfully with stressors (fight or flight); (2) 'Compromised social network', e.g. loneliness, in which the primary source of safety, i.e. being part of a cohesive social network, is lacking; and (3) 'Compromised contexts', e.g. chronic stress, in which daily contexts that are neutral by themselves may become unsafe via context conditioning. The great health risks of two of these ( 1 and 2) extremely common conditions have not hitherto been explained in terms of chronic stress.
The most important, and testable, implication of GUTS is this: rather than elucidating the signals of stressors or threat, GUTS implies that we should focus on identifying the key signals of safety. Whereas others have proposed seemingly similar ideas to the GUTS model there are some important differences. For example, Maier and colleagues (Amat et al., 2005; Maier et al., 2006; Maier, 2015) have noted that whereas most theories suggest that uncontrollability activates the stress response, they suggest that it is perceived control that actively inhibits the impact of stressors. Similarly, Porges (2004) in the context of social engagement proposed the concept of "neuroception" in which the nervous system continuously and mostly unconsciously evaluates risk. Both of these ideas are similar to GUTS with one major difference: they each rely on actual stressors or perceptions of risk whereas GUTS emphasizes that the stress response is the default response that is only "turned off" when safety is clearly perceived. Crucially, these safety signals are not by definition the counterparts of the signals of threat: for living organisms the absence of threat does not equal the presence of safety.

\section{Acknowledgements}

This work was supported by ZON-MW (Netherlands Organisation for Health Research and Development); TOP Grant nr. 40-00812-98-11029. We also thank Marian Brosschot for textual comments on a previous version of the text.

\section{References}

Ahern, G.L., Sollers, J.J., Lane, R.D., Labiner, D.M., Herring, A.M., Weinand, M.E., Thayer, J.F., 2001. Heart rate and heart rate variability changes in the intracarotid sodium amobarbital test. Epilepsia 42 (7), 912-921, http://dx.doi. org/10.1046/j.1528-1157.2001.042007912.x.

Amat, J., Baratta, M.V., Paul, E., Bland, S.T., Watkins, L.R., Maier, S.F., 2005. Medial prefrontal cortex determines how stressor controllability affects behavior and dorsal raphe nucleus. Nat. Neurosci. 8 (3), 365-371, http://dx.doi.org/10.1038/ nn1399.

Bar, M., Aminoff, E., Mason, M., Fenske, M., 2007. The units of thought. Hippocampus 17 (6), 420-428, http://dx.doi.org/10.1002/hipo.20287.

Berthoud, H.R., Neuhuber, W.L., 2000. Functional and chemical anatomy of the afferent vagal system. Auton. Neurosci. Basic Clin. 85 (1-3), 1-17, http://dx.doi org/10.1016/s1566-0702(00)00215-0.

Bosma, H., Peter, R., Siegrist, J., Marmot, M., 1998. Two alternative job stress models and the risk of coronary heart disease. Am. J. Public Health 88 (1), 68-74, http://dx.doi.org/10.2105/ajph.88.1.68.

Brosschot, J.F., Gerin, W., Thayer, J.F., 2006. The perseverative cognition hypothesis: a review of worry, prolonged stress-related physiological activation, and health. J. Psychosom. Res. 60 (2), 113-124, http://dx.doi.org/10. 1016/j.jpsychores.2005.06.074.

Brosschot, J.F., Verkuil, B., Thayer, J.F., 2010. Conscious and unconscious perseverative cognition: is a large part of prolonged physiological activity due to unconscious stress? J. Psychosom. Res. 69 (4), 407-416, http://dx.doi.org/10 1016/j.jpsychores.2010.02.002.

Brosschot, J.F., Verkuil, B., Thayer, J.F., 2016. The default response to uncertainty and the importance of perceived safety in anxiety and stress: an evolution-theoretical perspective. J. Anxiety Disord. 41, 22-34, http://dx.doi. org/10.1016/j.janxdis.2016.04.012.

Brosschot, J.F., 2010. Markers of chronic stress: prolonged physiological activation and (un)conscious perseverative cognition. Neurosci. Biobehav. Rev. 35 (1) 46-50, http://dx.doi.org/10.1016/j.neubiorev.2010.01.004.

Cacioppo, J.T., Cacioppo, S., Capitanio, J.P., Cole, S.W., 2015. The neuroendocrinology of social isolation. Annu. Rev. Psychol. 66, 733-767, http://dx.doi.org/10.1146/annurev-psych-010814-015240.

Chandola, T., Britton, A., Brunner, E., Hemingway, H., Malik, M., Kumari, M. Marmot, M., 2008. Work stress and coronary heart disease: what are the mechanisms? Eur. Heart J. 29 (5), 640-648, http://dx.doi.org/10.1093/ eurheartj/ehm584.

Christianson, J.P., Benison, A.M., Jennings, J., Sandsmark, E.K., Amat, J., Kaufman, R.D., Maier, S.F., 2008. The sensory insular cortex mediates the stress-buffering effects of safety signals but not behavioral control. J. Neurosci. 28 (50), 13703-13711, http://dx.doi.org/10.1523/jneurosci.4270-08.2008.

Coan, J.A., 2010. Adult attachment and the brain. J. Soc. Pers. Relat. 27 (2), 210-217, http://dx.doi.org/10.1177/0265407509360900.

Damasio, A., 1991. Somatic Markers and the Guidance of Behavior. Oxford University Press, New York, pp. 217-299.

Dale, L.P., Carroll, L.E., Galen, G., Hayes, J.A., Webb, K.W., Porges, S.W., 2009. Abuse history is related to autonomic regulation to mild exercise and psychological 
wellbeing. Appl. Psychophysiol. Biofeedback 34 (4), 299-308, http://dx.doi.org/ $10.1007 / \mathrm{s} 10484-009-9111-4$

Davidson, R.J., McEwen, B.S., 2012. Social influences on neuroplasticity: stress and interventions to promote well-being. Nat. Neurosci. 15 (5), 689-695.

Davies, C.D., Craske, M.G., 2015. Psychophysiological responses to unpredictable threat: effects of cue and temporal unpredictability. Emotion 15 (2), 195-200, http://dx.doi.org/10.1037/emo0000038.

Grillon, C., Baas, J.M.P., Cornwell, B., Johnson, L., 2006. Context conditioning and behavioral avoidance in a virtual reality environment: effect of predictability. Biol. Psychiatry 60 (7), 752-759, http://dx.doi.org/10.1016/j.biopsych.2006.03. 072.

Grillon, C., Pine, D.S., Lissek, S., Rabin, S., Bonne, O., Vythilingam, M., 2009. Increased anxiety during anticipation of unpredictable aversive stimuli in posttraumatic stress disorder but not in generalized anxiety disorder. Biol. Psychiatry 66 (1), 47-53, http://dx.doi.org/10.1016/j.biopsych.2008.12.028.

Grupe, D.W., Nitschke, J.B., 2013. Uncertainty and anticipation in anxiety: an integrated neurobiological and psychological perspective. Nat. Rev. Neurosci. 14 (7), 488-501, http://dx.doi.org/10.1038/nrn3524.

Hawkley, L.C., Burleson, M.H., Berntson, G.G., Cacioppo, J.T., 2003. Loneliness in everyday life: cardiovascular activity, psychosocial context, and health behaviors. J. Pers. Soc. Psychol. 85 (1), 105-120, http://dx.doi.org/10.1037/ 0022-3514.85.1.105.

Heitkemper, M.M., Cain, K.C., Burr, R.L., Jun, S.E., Jarrett, M.E., 2011. Is childhood abuse or neglect associated with symptom reports and physiological measures in women with irritable bowel syndrome? Biol. Res. Nurs. 13 (4), 399-408, http://dx.doi.org/10.1177/1099800410393274.

Hoehn-Saric, R., McLeod, D.R., Funderburk, F., Kowalski, P., 2004. Somatic symptoms and physiologic responses in generalized anxiety disorder and panic disorder-an ambulatory monitor study. Arch. Gen. Psychiatry 61 (9), 913-921, http://dx.doi.org/10.1001/archpsyc.61.9.913.

Hughlings Jackson, J., March 1884. Evolution and dissolution of the nervous system. Croonian lectures delivered at the Royal College of Physicians, Lecture II, March 1884. Br. Med. J. 1 (1214), 660-663.

Jarczok, M.N., Li, J., Mauss, D., Fischer, J.E., Thayer, J.F., 2013. Heart rate variability is associated with glycemic status after controlling for components of the metabolic syndrome. Int. J. Cardiol. 167 (3), 855-861, http://dx.doi.org/10. 1016/j.ijcard.2012.02.002.

Jarczok, M.N., Koenig, J., Mauss, D., Fischer, J.E., Thayer, J.F., 2014. Lower heart rate variability predicts increased level of C-reactive protein 4 years later in healthy, nonsmoking adults. J. Intern. Med. 276 (6), 667-671, http://dx.doi.org/ 10.1111/joim.12295.

Jarczok, M.N., Kleber, M.E., Koenig, J., Loerbroks, A., Herr, R.M., Hoffmann, K. Thayer, 2015. Investigating the associations of self-rated health: heart rate variability is more strongly associated than inflammatory and other frequently used biomarkers in a cross sectional occupational sample. PLoS One 10 (2), http://dx.doi.org/10.1371/journal.pone.0117196.

Julius, S., 1995. The defense reaction - a common denominator of coronary risk and blood-pressure in neurogenic hypertension. Clin. Exp. Hypertens. 17 (1-2), 375-386, http://dx.doi.org/10.3109/10641969509087078.

Kiecolt-Glaser, J.K., McGuire, L., Robles, T.F., Glaser, R., 2002. Psychoneuroimmunology: psychological influences on immune function and health. J. Consult. Clin. Psychol. 70 (3), 537-547, http://dx.doi.org/10.1037// 0022-006x.70.3.537.

Kim, M.J., Whalen, P.J., 2009. The structural integrity of an amygdala-prefrontal pathway predicts trait anxiety. J. Neurosci. 29 (37), 11614-11618, http://dx doi.org/10.1523/jneurosci.2335-09.2009.

Kim, H., Somerville, L.H., Johnstone, T., Alexander, A.L., Whalen, P.J., 2003. Inverse amygdala and medial prefrontal cortex responses to surprised faces. Neuroreport 14 (18), 2317-2322, http://dx.doi.org/10.1097/01.wnr. 0000101520.44335 .20$.

Kim, M.J., Gee, D.G., Loucks, R.A., Davis, F.C., Whalen, P.J., 2011a. Anxiety dissociates dorsal and ventral medial prefrontal cortex functional connectivity with the amygdala at rest. Cereb. Cortex 21 (7), 1667-1673, http://dx.doi.org/10.1093/ cercor/bhq237.

Kim, M.J., Loucks, R.A., Palmer, A.L., Brown, A.C., Solomon, K.M., Marchante, A.N., Whalen, P.J., 2011b. The structural and functional connectivity of the amygdala: from normal emotion to pathological anxiety. Behav. Brain Res. 223 (2), 403-410, http://dx.doi.org/10.1016/j.bbr.2011.04.025.

Krantz, D.S., McCeney, M.K., 2002. Effects of psychological and social factors on organic disease: a critical assessment of research on coronary heart disease. Annu. Rev. Psychol. 53, 341-369, http://dx.doi.org/10.1146/annurev.psych.53. 100901.135208 .

Kubala, K.H., Christianson, J.P., Kaufman, R.D., Watkins, L.R., Maier, S.F., 2012. Short- and long-term consequences of stressor controllability in adolescent rats. Behav. Brain Res. 234 (2), 278-284, http://dx.doi.org/10.1016/j.bbr.2012. 06.027 .

Kubzansky, L.D., Kawachi, I., 2000. Going to the heart of the matter: do negative emotions cause coronary heart disease? J. Psychosom. Res. 48 (4-5), 323-337, http://dx.doi.org/10.1016/s0022-3999(99)00091-4.

Kuo, T.B.J., Lai, C.J., Huang, Y.T., Yang, C.C.H., 2005. Regression analysis between heart rate variability and baroreflex-related vagus nerve activity in rats. J. Cardiovasc. Electrophysiol. 16 (8), 864-869, http://dx.doi.org/10.1111/j.15408167.2005.40656.x.

Lee, S., Colditz, G.A., Berkman, L.F., Kawachi, I., 2003. Caregiving and risk of coronary heart disease in US women-a prospective study. Am. J. Prev. Med. 24 (2), 113-119, http://dx.doi.org/10.1016/s0749-3797(02)00582-2.
Licht, C.M.M., de Geus, E.J.C., van Dyck, R., Penninx, B., 2009. Association between anxiety disorders and heart rate variability in The Netherlands Study of Depression and Anxiety (NESDA). Psychosom. Med. 71 (5), 508-518, http://dx. doi.org/10.1097/PSY.0b013e3181a292a6.

Maier, S.F., 2015. Behavioral control blunts reactions to contemporaneous and future adverse events: medial prefrontal cortex plasticity and a corticostriatal network. Neurobiol. Stress 1, 12-22.

Maier, S.F., Amat, J., Baratta, M.V., Paul, E., Watkins, L.R., 2006. Behavioral control, the medial prefrontal cortex, and resilience. Dialogues Clin. Neurosci. 8 (4), 353-374.

Maren, S., Phan, K.L., Liberzon, I., 2013. The contextual brain: implications for fear conditioning, extinction and psychopathology. Nat. Rev. Neurosci. 14 (6), 417-428, http://dx.doi.org/10.1038/nrn3492.

Matthews, K.A., Gump, B.B., 2002. Chronic work stress and marital dissolution increase risk of posttrial mortality in mien from the multiple risk factor intervention trial. Arch. Intern. Med. 162 (3), 309-315, http://dx.doi.org/10 1001/archinte.162.3.309.

Mayer, E.A., 2011. Gut feelings: the emerging biology of gut-brain communication. Nat. Rev. Neurosci. 12 (8), 453-466, http://dx.doi.org/10.1038/nrn3071.

McEwen, B.S., Seeman, T., 1999. Protective and damaging effects of mediators of stress-elaborating and testing the concepts of allostasis and allostatic load. In Adler, N.E., Marmot, M., McEwen, B., Stewart, J. (Eds.), Socioeconomic Status and Health in Industrial Nations: Social, Psychological, and Biological Pathways, vol. 896, pp. 30-47.

Melzig, C.A., Weike, A.I., Hamm, A.O., Thayer, J.F., 2009. Individual differences in fear-potentiated startle as a function of resting heart rate variability: implications for panic disorder. Int. J. Psychophysiol. 71 (2), 109-117, http:// dx.doi.org/10.1016/j.ijpsycho.2008.07.013.

Mineka, S., Kihlstrom, J.F., 1978. Unpredictable and uncontrollable events-new perspective on experimental neurosis. J. Abnorm. Psychol. 87 (2), 256-271, http://dx.doi.org/10.1037//0021-843x.87.2.256.

Motzkin, J.C., Philippi, C.L., Wolf, R.C., Baskaya, M.K., Koenigs, M., 2015 Ventromedial prefrontal cortex is critical for the regulation of amygdala activity in humans. Biol. Psychiatry 77 (3), 276-284, http://dx.doi.org/10.1016/ j.biopsych.2014.02.014.

Nesse, R.M., 2005. Natural selection and the regulation of defenses-a signal detection analysis of the smoke detector principle. Evol. Hum. Behav. 26 (1), 88-105, http://dx.doi.org/10.1016/j.evolhumbehav.2004.08.002.

Nielsen, M.B., Hetland, J., Matthiesen, S.B., Einarsen, S., 2012. Longitudinal relationships between workplace bullying and psychological distress. Scand. J. Work Environ. Health 38 (1), 38-46, http://dx.doi.org/10.5271/sjweh.3178.

Orth-Gomer, K., Wamala, S.P., Horsten, M., Schenck-Gustafsson, K., Schneiderman, N., Mittleman, M.A., 2000. Marital stress worsens prognosis in women with coronary heart disease-the Stockholm Female Coronary Risk Study. J. Am. Med. Assoc. 284 (23), 3008-3014, http://dx.doi.org/10.1001/jama.284.23.3008.

Ottaviani, C., Lonigro, A., Medea, B., Couyoumdjian, A., Thayer, J.F., Verkuil, B. Brosschot, J.F., 2015. Physiological concomitants of perseverative cognition: a systematic review and meta-analysis. Psychol. Bull., Advance online publication.

Pappens, M., Schroijen, M., Sutterlin, S., Smets, E., Van den Bergh, O., Thayer, J.F., Van Diest, I., 2014. Resting heart rate variability predicts safety learning and fear extinction in an interoceptive fear conditioning paradigm. PLoS One $9(9)$, http://dx.doi.org/10.1371/journal.pone.0105054.

Porges, S.W., 2004. Neuroception: a subconscious system for detecting threat and safety. Zero to Three: Bull. Natl. Cent. Clin. Infant Progr. 24 (5), 19-24.

Porges, S.W., 2007. The polyvagal perspective. Biol. Psychol. 74 (2), 116-143, http://dx.doi.org/10.1016/j.biopsycho.2006.06.009.

Proffitt, D.R., 2006. Embodied perception and the economy of action. Perspect. Psychol. Sci. 1 (2), 110-122, http://dx.doi.org/10.1111/j. 1745-6916.2006. 00008.x.

Quirk, G.J., Gehlert, D.R., 2003. Inhibition of the amygdala: key to pathological states? In: ShinnickGallagher, P., Pitkanen, A., Shekhar, A., Cahill, L. (Eds.), Amygdala in Brain Function: Bacic and Clinical Approaches, vol. 985, pp. 263-272.

Robles, T.F., Kiecolt-Glaser, J.K., 2003. The physiology of marriage: pathways to health. Physiol. \& Behav. 79 (3), 409-416, http://dx.doi.org/10.1016/s0031 9384(03)00160-4.

Roest, A.M., Martens, E.J., de Jonge, P., Denollet, J., 2010. Anxiety and risk of incident coronary heart disease a meta-analysis. J. Am. Coll. Cardiol. 56 (1), 38-46, http://dx.doi.org/10.1016/j.jacc.2010.03.034.

Rosengren, A., Hawken, S., Ounpuu, S., Sliwa, K., Zubaid, M., Almahmeed, W.A. Investigators, I., 2004. Association of psychosocial risk factors with risk of acute myocardial infarction in 11119 cases and 13648 controls from 52 countries (the INTERHEART study): case-control study. Lancet 364 (9438), 953-962, http://dx.doi.org/10.1016/s0140-6736(04)17019-0.

Ruiz-Padial, E., Sollers, J.J., Vila, J., Thayer, J.F., 2003. The rhythm of the heart in the blink of an eye: emotion-modulated startle magnitude covaries with heart rate variability. Psychophysiology 40 (2), 306-313, http://dx.doi.org/10.1111/14698986.00032

Sakaki, M., Yoo, H.J., Nga, L., Le, e.T.H., Thayer, J.F., Mather, M., 2016. Heart rate variability is associated with amygdala functional connectivity with MPFC across younger and older adults. Neuroimage 139, 44-52, http://dx.doi.org/10. 1016/j.neuroimage.2016.05.076

Searle, A., Bennett, P., 2001. Psychological factors and inflammatory bowel disease: a review of a decade of literature. Psychol. Health Med. 6 (2), 14. 
Smith, R., Allen, J.J.B., Thayer, J.F., Lane, R.D., 2015. Altered functional connectivity between medial prefrontal cortex and the inferior brainstem in major depression during appraisal of subjective emotional responses: a preliminary study. Biol. Psychol. 108, 13-24, http://dx.doi.org/10.1016/j.biopsycho.2015. 03.007.

Steptoe, A., Shankar, A., Demakakos, P., Wardle, J., 2013. Social isolation, loneliness, and all-cause mortality in older men and women. Proc. Natl. Acad. Sci. U. S. A. 110 (15), 5797-5801, http://dx.doi.org/10.1073/pnas.1219686110.

Thayer, J.F., 2007. What the heart says to the brain (and vice versa) and why we should listen. Psycholog. Top. 16 (2), 241-250.

Thayer, J.F., Fischer, J.E., 2009. Heart rate variability, overnight urinary norepinephrine and C-reactive protein: evidence for the cholinergic anti-inflammatory pathway in healthy human adults. J. Intern. Med. 265 (4), 439-447, http://dx.doi.org/10.1111/j. 1365-2796.2008.02023.x.

Thayer, J.F., Fischer, J.E., 2013. Heart rate variability, overnight urinary norepinephrine, and plasma cholesterol in apparently healthy human adults. Int. J. Cardiol. 162 (3), 240-244, http://dx.doi.org/10.1016/j.ijcard.2011.05.058.

Thayer, J.F., Friedman, B.H., Borkovec, T.D., 1996. Autonomic characteristics of generalized anxiety disorder and worry. Biol. Psychiatry 39 (4), 255-266, http://dx.doi.org/10.1016/0006-3223(95)00136-0.

Thayer, J.F., Sollers, J.J., Labiner, D.M., Weinand, M., Herring, A.M., Lane, R.D., Ahern, G.L., 2009. Age-related differences in prefrontal control of heart rate in humans: a pharmacological blockade study. Int. J. Psychophysiol. 72 (1), 81-88, http://dx.doi.org/10.1016/j.ijpsycho.2008.04.007.

Thayer, J.F., Yamamoto, S.S., Brosschot, J.F., 2010. The relationship of autonomic imbalance, heart rate variability and cardiovascular disease risk factors. Int. J. Cardiol. 141 (2), 122-131, http://dx.doi.org/10.1016/j.ijcard.2009.09.543.

Thayer, J.F., Ahs, F., Fredrikson, M., Sollers III, J.J., Wager, T.D., 2012. A meta-analysis of heart rate variability and neuroimaging studies: implications for heart rate variability as a marker of stress and health. Neurosci. Biobehav. Rev. 36 (2), 747-756, http://dx.doi.org/10.1016/j.neubiorev.2011.11.009.

Tost, H., Champagne, F.A., Meyer-Lindenberg, A., 2015. Environmental influence in the brain, human welfare and mental health. Nat. Neurosci. 18 (10), 1421-1431, http://dx.doi.org/10.1038/nn.4108.

Trimmer, P.C., Paul, E.S., Mendl, M.T., McNamara, J.M., Houston, A.I., 2013. On the evolution and optimality of mood states. Behav. Sci. 3, 501-521.

Tully, P.J., Cosh, S.M., Baune, B.T., 2013. A review of the affects of worry and generalized anxiety disorder upon cardiovascular health and coronary heart disease. Psychol. Health Med. 18 (6), 627-644, http://dx.doi.org/10.1080/ 13548506.2012 .749355$.

Urry, H.L., van Reekum, C.M., Johnstone, T., Kalin, N.H., Thurow, M.E., Schaefer, H.S., Jackson, C.A., Frye, C.J., Greischar, L.L., Alexander, A.L., Davidson, R.J., 2006 Amygdala and ventromedial prefrontal cortex are inversely coupled during regulation of negative affect and predict the diurnal pattern of cortisol secretion among older adults. J. Neurosci. 26 (16), 4415-4425, http://dx.doi. org/10.1523/jneurosci.3215-05.2006. van Harmelen, A.L., van Tol, M.J., van der Wee, N.J.A., Veltman, D.J., Aleman, A. Spinhoven, P., Elzinga, B.M., 2010. Reduced medial prefrontal cortex volume in adults reporting childhood emotional maltreatment. Biol. Psychiatry 68 (9), 832-838, http://dx.doi.org/10.1016/j.biopsych.2010.06.011.

van Marle, H.J.F., Hermans, E.J., Qin, S., Fernandez, G., 2010. Enhanced resting-state connectivity of amygdala in the immediate aftermath of acute psychological stress. Neuroimage 53 (1), 348-354, http://dx.doi.org/10.1016/j.neuroimage. 2010.05.070

Verkuil, B., Brosschot, J.F., Gebhardt, W., Thayer, J.F., 2010. When worries make you sick: a review of perseverative cognition: the default stress response and somatic health. J. Exp. Psychopathol. 1 (1), 87-118.

Verkuil, B., Atasayi, S., Molendijk, M.L., 2015. Workplace bullying and mental health: a meta-analysis on cross-sectional and longitudinal data. PLoS One 10 (8), http://dx.doi.org/10.1371/journal.pone.0135225.

Vitaliano, P.P., Scanlan, J.M., Zhang, J.P., Savage, M.V., Hirsch, I.B., Siegler, I.C., 2002 A path model of chronic stress, the metabolic syndrome, and coronary heart disease. Psychosom. Med. 64 (3), 418-435.

Waldvogel, D., van Gelderen, P., Muellbacher, W., Ziemann, U., Immisch, I., Hallett, M., 2000. The relative metabolic demand of inhibition and excitation. Nature 406 (6799), 995-998.

Weiss, J.M., 1970. Somatic effects of predictable and unpredictable shock. Psychosom. Med. 32 (4) (397-\&).

Wendt, J., Neubert, J., Koenig, J., Thayer, J.F., Hamm, A.O., 2015. Resting heart rate variability is associated with inhibition of conditioned fear. Psychophysiology 52 (9), 1161-1166, http://dx.doi.org/10.1111/psyp.12456.

Woody, S., Rachman, S., 1994. Generalized anxiety disorder (GAD) as an unsuccessful search for safety. Clin. Psychol. Rev. 14 (8), 743-753, http://dx. doi.org/10.1016/0272-7358(94)90040-x.

Yang, Y.C., Boena, C., Gerkena, K., Schorpp, K., Mullan Harris, K., 2016. Social relationships and physiological determinants of longevity across the human life span. PNAS, http://dx.doi.org/10.1073/pnas.1511085112, Epub.

Zoccola, P.M., Dickerson, S.S., 2012. Assessing the relationship between rumination and cortisol: a review. J. Psychosom. Res. 73 (1), 1-9, http://dx.doi.org/10. 1016/j.jpsychores.2012.03.007.

Zulfiqar, U., Jurivich, D.A., Gao, W., Singer, D.H., 2010. Relation of high heart rate variability to healthy longevity. Am. J. Cardiol. 105 (8), 1181-1185, http://dx doi.org/10.1016/j.amjcard.2009.12.022. 